\title{
Knowledge - Based Innovation for Sustainable Competitive Advantage
}

\author{
W M I Udayanganie \\ University of Ruhuna, Sri Lanka
}

Received: Dec. 1, 2020 Accepted: Feb. 7, 2021 Online published: Feb. 23, 2021

doi:10.5296/ijhrs.v11i1.18016 URL: https://doi.org/10.5296/ijhrs.v11i1.18016

\begin{abstract}
We live in an era which is an interval of significant technological as well as economic and social shifts. This is elucidated by the move from a traditional society based on industry to a modern knowledge-based society. Most important aspect of this is not the increase in production volumes and forms. Rather it is the emergence of novel and fundamentally novel knowledge. Above mentioned society would therefore focus on new knowledge to produce new goods and technologies. It also looks into different ways of economic, manufacturing, ecological, humanitarian and social governance. This study explores the potential of translating knowledge, creativity and innovation into an efficient definition of a product. Obviously, the present century is a period of change in quality and lives of people on grounds of creativity and innovation. Two main practices for businesses are knowledge management and innovation. Management of knowledge is regarded as a key management strategy when it comes to the present period of economy which is a knowledge - based one. Ever growing competition, consumer demands and novel avenue for business has created the necessity for innovation by companies. The key position of knowledge management in innovation must be understood due to the fact that it exerts an important impact on innovation. The importance of this work lays on how knowledge management aid organizations to improve innovation of its products and services to achieve competitive advantage. This also aims to add on to literature by providing a working definition of innovation which is outcome-oriented and at the same time based on comprehensive knowledge.
\end{abstract}

Keywords: knowledge, innovation, competitive advantage

\section{Introduction}

Innovation has become the central part of businesses in today's rapidly changing business world. Rapid pace of new product development, narrow lifecycles of a product as well as swiftly changing technologies, has made the speed of innovation possible. This has led to the alteration of the essence of global economic growth. Growth in the amount of knowledge 
available to enterprises has improved the sophistication of creativity.

At this point, the development of society is knowledge-based. Further it is clear that only those systems which produce, growth and those which could assess knowledge can be regarded to be efficient. In addition, commerce in such developed economies are already metamorphosing expertise and innovation from the processing of raw materials into the processing of information. This drift in progression of society and economy is called the "third wave". This suggests that world's developed economies are already being transformed into information and knowledge-based organizational systems. It forces businesses, for their part, to developing their knowledge base constantly so that they adjust to the newer condition which is regarded as a significant competitive advantage. When it comes to accumulation of expertise, persistent rally is there which is mostly designed on a corporate basis. Because of that Awareness is regarded to be the single most significant economic reserve for gaining a sustainable corporate outcome. The gathering knowledge and its conversion into creativity are connected to all sources of the fight for the benefit of companies. Individual who continuously adjusts to the fluctuating discrepancy between the ability to utilize knowledge and the circumstances in practice for its application as goods, procedures etc. needs Knowledge as an internal need. Novel requirement for knowledge shall be developed, identifying the duel phases of the production of innovation: speech and opportunity; in other words, the generation of innovation and the creation of grounds for the realization of its product.

The accumulation of knowledge and its transformation into creativity are connected to all avenues for the fight for viable benefits of an organization. An individual who continuously accustomed to the evolving discrepancy between the ability to utilize knowledge and the practical situations for its use as goods, procedures and so on, demands Knowledge as an internal need. Recognizing speech and opportunity, which represent the duel phase formation of innovation, a novel human requisite for knowledge is due to be developed (Tomov, P,2015, 22-24). The foundation of this creation is the process of invention, which is a creative process which includes the entire innovation cycle, including operation, from birth to production and realization, conception, design, production and realization.

\section{Literature Review}

\subsection{Traditional Innovation}

Innovation requires a result with the mechanism at the same time to achieve this outcome. Innovation has been identified as the first, centered on the seminal work of Schumpeter (1934), the implementation of a new product, procedure, operation, or framework. It illustrates the dual definition of the essence of innovation as a method (introduction) as well as an outcome (product, process, Process, Scheme). "The process of innovation is defined as "getting into use" (Kanter, 1984, p. 20), "introduction and application" (West and Farr, 1990, p. 9) or "development and implementation" (West and Farr, 1990, p. 9). Implementation" of an idea (Van de Ven, 1986, p. 590). When the emphasis of the description is on the as a result, innovation is characterized as goods, processes, software, ideas, concepts, etc. New to the environment in which it is being applied (Damanpour, 1991; Dougherty, 1992a; Howell and 
Higgins, 1990; Pennings and Harianto, 1992; Marcus, 1988).

Innovation is a complicated system that requires a number of variables at various levels (Kong \& Li, 2007). The mechanism of creativity and the influences that influence it should be organized and consistently controlled. Innovation concepts are just as broad as the number of scholars who have researched the idea (Katz \& Preez, 2008). A potential explanation for this is the number of diverse fields that have centered their attention on creativity and a concept has been developed based on their unique viewpoints and experiences. Any patterns appear to be replicated in the literature, considering these variations.

Innovation excellence needs companies to be able to respond quickly to changes in their market situation and to recognise and take advantage of new opportunities through the creation of innovative solutions (Martensen and Dahlgaard (1999) ). Katz \& Preez, (2008) explained that, A variety of business attributes have been described that have been shown to increase the capacity of an organization to adapt quickly, effectively and innovatively to change. The variations in the usage of operational principles based on the scale of the enterprise and technical intensity have been analyzed by Palcic et al. They also address developments in the use of principles of business innovation and organizations' future strategies. They illustrate that the use of particular principles of technological and operational advancement is extremely diverse.

\subsection{Knowledge Based Innovation}

The literature on innovation which based on knowledge explores the knowledge contented of an innovation with an emphasis on three specific areas: the meaning of the knowledge concept in organizations, the development of knowledge in the process of innovation and processes by which innovation relates to knowledge. Typically, the three areas of knowledge, innovation, competitive advantage are orientated towards explanation of knowledge' s role in the innovation process. Different versions of a knowledge-based innovation method can be found in literature (e.g., Galunic and Rodan, 1998; Takeuchi and Nonaka, 1995).

Those models explore the features of awareness and its effect on the process of knowledge formation, whose output is implicitly seen as an innovation. Tsai and Ghoshal (1998) and Tsai (2001), for instance, are present organizational innovation models that draw a parallel between the creation of knowledge and innovation. While these models highlight the position of different knowledge development processes and for the development of new knowledge, and recombination, they usually fail to decide whether is it possible to explicitly view this new information as an invention.

\subsection{Knowledge Management}

According to Grover \& Davenport (2001)" In many aspects of the business, knowledge is integrated and "knowledge management can be framed as the challenge of developing an efficient and effective operational knowledge marketplace". In order to foster efficient and more consistent decision-making, Probst et al. (2000) proposed knowledge management as the management of the organizational knowledge and information resources of an organization and its business processes. Knowledge management is recognized in enterprises 
in a constantly changing world as the fundamental practice for acquiring, increasing and maintaining creativity (Malhotra, 2000). Davenport and Grover (2001) and Liebowitz (2000) promote the long-term sustainability and development of the effective use of the company's organizational expertise through its business processes. Knowledge management is defined by Nonaka and Takeuchi (1995) as the management of certain systems that control knowledge generation, dissemination and usage. Organizational knowledge is influenced by organizational rituals, symbols, traditions and standards of behavior, etc., i.e. the culture of the organization that has been built over time and is thus unique to the organisation. The corporate culture, therefore is a fragile, unique and imperfectly imitable one. In the modern economy, the strategic value of corporate expertise has emerged, as individuals quickly transfer from companies taking their interactions with them due to the globalization of the economies. It is focused on the life cycle of knowledge management: knowledge formation, storing and retrieval of knowledge, transmission of knowledge and application of knowledge.

At various levels within the organisation, from the person level to the external level, information management cycles can occur (Rounti, 2009). The implementation of the said viewpoint is essential because it might allow one to recognize which levels are better or weaker in organisations, If one of them is more significant than the others, etc. Information management cycles may occur at different levels within the company, from the individual level to the external level (Rounti, 2009). The introduction of this point of view is also very helpful because it might allow one to identify which levels of organizations are stronger or worse, whether some of them are more important than others, etc.

\subsection{The Connection between Knowledge and Innovation}

Enterprises are integrated organizational process networks and organizations with knowledge. For innovation, new knowledge is necessary, but it reduces the benefits of knowledge the valuability of knowledge depends on its impact. Effective innovation involves the interaction between knowledge and operating processes in one way or another new knowledge, on the other hand, is introduced into the new stream (Kanter, 1989) and innovation is essential to new knowledge. As Schumpeter pointed out, Innovation is not only the invention of something new, but the sale of this invention is also, more importantly (Schumpeter, 1934). Novelty factor and marketing are two important characteristics to identify innovation from this point of view. From the perspective of knowledge or the management of knowledge, innovation comes from the development of knowledge and marketing is done through the application of knowledge. The newly generated knowledge contributes to the required variety to progress and recreate organisations, although the utilization of knowledge contributes towards enhancing efficiency or generating value. The development and implementation of knowledge are therefore two fundamental aspects of innovation. The development of knowledge is related to the innovation process that creates new knowledge. The application of knowledge is the way to grasp the hidden potential of knowledge. The implementation of knowledge. Innovation that creates new value through an organization's information capital is a knowledge management sector. The creation of modern organizational services, products and procedures in today's world has been especially significant with regard to innovation (Bornemann et al. 2003). Innovation means regeneration and transformation. The emergence 
and applying of the new knowledge is essential for innovation and illustrates the strong relations of knowledge and innovation. Kosturiak, 2010: Innovation creates value via knowledge. Knowledge management consists of a collection of systems, policies and methods linking employee knowledge to the development of creative solutions with new value sources (products, services, processes). Innovation is a systemic and fundamental improvement that offers consumers a new benefit who are willing to pay for it (Zeleny, 2005).

As the major attraction of the organization, the innovation process must be created. As for the major attraction of the organization, the innovation process must be created. Four fundamental issues arise in knowledge management and innovation study, as Van de Ven and Engleman (2004) have reported. The first is the human problem of how organisations become inventive by seeking new knowledge rather than utilizing established knowledge. Secondly, there is the process of creating a process that handles and applies concepts. The third relates to a systemic issue of infrastructure building across organizational borders in order to consume and gain information and to encourage, support and promote innovation activities. The final topic deals with the management problem of the development and management of an innovation-specific context. These four topics have been studied by researchers of both internally and externally influencing Knowledge Management and innovative strategies. Internal considerations include organizational structures, processes for monitoring and coordination, collaboration and organizational cultures. External variables provide a variety of contingencies that affect the activities of Knowledge Management and innovation. The knowledge base vision, but less well known is the specification on the relation to innovation (Johnston \& Paladino 2007), has put much effort into understanding forms, knowledge development and the relation between Individual knowledge and organizational training and other issues.

\section{Innovation as a Result of Knowledge Management.}

Knowledge literature describes the pre-requisite for current knowledge a process of innovation must take place, making path-dependence a crucial problem. For example, absorption capacity is the same as the creative capacity of a business, and this is seen as a variable of the previous Knowledge (Cohen and Levinthal, 1990). A very low knowledge level lead innovation ability to be "locked-out" in case the degree of information is so distant behind it that it gets to be "locked-out "unable to acquire the requisite path- dependent information.

Although knowledge is a pre-requisite for innovation, the initiator of the innovation process is not commonly considered. Nonaka and Takeuchi (1995) layout a prepare of development that begins with concerns being generated and identified by an organization. As innovation starts with a dilemma, tacit knowledge becomes essential, partly because of the effect of reliance on the road, but also because it guides further knowledge creation or anticipates the ultimate solution.

Initially, the processes relating to knowledge and innovation are frequently examined in discourses of organizational capabilities and the company's knowledge-based perspective. 
Kogut and Zander (1992) assert that the combinational capacity of a firm drives innovation. That is the dynamic capacity of the organization to synthesize and apply expertise in combination with the "technology's new potential (Kogut and Zander, 1992, p. 391) enables an organization to create novel applications from existing information. Additionally, Grant (1996) argues that information integration is essential for competitive advantage which this integration takes place through course, schedules and an ability progression.

Innovation has long been thought of as information -intensive in literature (Kanter, 1988), and knowledge has been recognized to play an important role as an organizational feature in promoting innovation (Dougherty, 1992b). Innovation models detail the form of information processes that promote the production of knowledge in the knowledge literature (Nonaka, 1994; Galunic and Rodan, 1998). They may not explicitly define, however, what the result of their method of creativity is. Innovation is basically new knowledge, and that innovation can therefore be conceptualized as an outcome from a knowledge- based perspective.

This article adds to the literature of innovation by presenting a s system to comprehend the literature of innovation and make sense of the variety of the innovation concept's meanings and operationalization.

\section{Conclusion}

In conclusion, knowledge may be believed to be the basis or foundation for the development of an innovative concept. And the effectiveness of applying this description depends on the types, methods and methods for quicker and more realistic implementation and faster application execution. The new criteria for production also suggest a radically new type of industrial construction. By the use of global knowledge networks, production can be stepped up and the quality of the goods produced can be greatly improved. By the use of global knowledge networks, production can be stepped up and the quality of the goods produced can be greatly improved.

Innovations are a priority for the development of environmentally sustainable technical schemes, methods and processes. In this regard, social issues and environmental constraints would exert their pre-eminence on the growth of innovation in production in the future. In addition, productivity and quality, determined by the collection of factors that are produced by the impact of new technologies, will have an integral significance. These new high efficiency technologies are a direct product of taking advantage of the latest developments in computer technology and innovation.

This study promotes the idea of the management of knowledge and ties it to innovation. The literature review found that there is a strong correlation between the management of knowledge and innovation. Knowledge practices such as knowledge acquisition, management, sharing, learning, reuse and retrieval also play an important role in bringing innovation to the market. Innovation means that new concepts, methods, goods or services are created, embraced, and implemented. It is clear that the management of expertise is closely linked to organizational creativity. Many scholars emphasize the significance of such an orientation to 
improve the potential for creativity. In contrast to those organizations that don't concentrate on this aspect, organizations that quickly capture and incorporate new information through the enterprise will be able to encourage innovation.

\section{References}

Cohen, W. M., \& Levinthal, D. A. (1990). Absorptive capacity: A new perspective on learning and innovation. Administrative Science Quarterly, 35, 128-152. https://doi.org/10.2307/2393553

Damanpour, F. (1991). Organizational innovation: A meta-analysis of effects of determinants and moderators. Academy of Management Journal, 34, 555-590. https://doi.org/10.5465/256406

Grant, R. M. (1996). Toward a knowledge-based theory of the firm. Strategic Management Journal, 17, 109-122. https://doi.org/10.1002/smj.4250171110

Grover, V., \& Davenport, T. H. (2001). General Perspectives on Knowledge Management: Fostering a Research Agenda. Journal of Management Information Systems, 18(1), 5-21, 0742-1222. https://doi.org/10.1080/07421222.2001.11045672

Johnston, S., \& Paladino, A. (2007). Knowledge Management and Involvement in Innovations in MNC Subsidiaries. Management International Review, 47(2), 281-302. https://doi.org/10.1007/s11575-007-0016-2

Kanter, R. M. (1989). Swimming in newstreams: mastering innovation dilemmas. California Management Review, 31(4), 45-69. https://doi.org/10.2307/41166582

Kanter, R. M. (1984). The Change Masters: Innovation and Entrepreneurship in the American Corporation, Simon and Schuster, New York, NY.

Kanter, R. M. (1988). When a thousand flowers bloom. Staw, B. M. and Cummings, L. L. (Eds.), Research in Organizational Behavior, Vol. 10, JAI Press, Greenwich, CT, pp. 169-211.

Katz, B., \& Preez, N. D. (2008). The Role of Knowledge Management in Supporting a Radical Innovation Project, In: Methods and Tools for Effective Knowledge LifeCycle-Management, Editors: Bernard A. \& Tischkiewitsch S., 331-345, Springer, ISBN 978-3-540-78430-2, Berlin Heidelberg. https://doi.org/10.1007/978-3-540-78431-9_18

Kogut, B., \& Zander, U. (1992). Knowledge of the firm, combinative capabilities, and the replication of technology", Organization Science, 3, 383-397. https://doi.org/10.1287/orsc.3.3.383

Kong, X. Y., \& Li, X. Y. (2007). A Systems Thinking Model for Innovation Management: The Knowledge Management Perspective. Procedings of 2007 International Conference on Management Science \& Engineering (14th), Yin Ji-rong, pp 1499-1504, ISBN 978-5603-2278-0, Harbin, Aug. 2007, Harbin Institute of Technology Press, Harbin, China

Kosturiak, J. (2010). Innovations and knowledge management. Human Systems Management, 29, 51-63. https://doi.org/10.3233/HSM-2010-0713 


\section{Macrothink}

International Journal of Human Resource Studies ISSN 2162-3058 2021, Vol. 11, No. 1

Malhotra, Y. (2000). Knowledge Management for E-business Performance. Information

Strategy: The Executives Journal, 16(4), 5-16. https://doi.org/10.1080/07438613.2000.10744620

Martensen, A., \& Dahlgaard, J. J. (1999). Strategy and planning for innovation management supported by creative and learning organisations. International Journal of Quality \& Reliability Management, 16(9), 878-891. https://doi.org/10.1108/02656719910289177

Nonaka, I., \& Takeuchi, H. (1995). The Knowledge-creating Company: How Japanese Companies Create the Dynamics of Innovation, Oxford University Press, ISBN 0195092694, New York.

Nonaka, I. (1994). A dynamic theory of organizational knowledge creation. Organization Science, 5, 14-37. https://doi.org/10.1287/orsc.5.1.14

Nonaka, I., \& Takeuchi, H. (1995). The Knowledge Creating Company: How Japanese Companies Create the Dynamics of Innovation, Oxford University Press, New York.

Probst, G., Raub, S., \& Romhardt, K. (2000). Managing knowledge: building blocks for success, John Wiley, ISBN 978-0-471-99768-9, Chichester.

Rounti, I. S. (2009). Innovation Culture for Knowledge Management in new e-Ra. In: Web 2.0 The Business Model, Miltiadis D. L., Ernesto D., Patricia Ordonez de P., 293-307, Springer Science+Business Media, ISBN 978-0-387-85894-4, New York.

Schumpeter, J. A. (1934). Theory of Economic Development, Harvard University Press, Cambridge, MA.

Tomov, P. Innovative solutions for the automation of discrete production engineering, 12th International conference "Standardization, prototypes and quality: a means of balkan countries' colloboration", Kocaeli, 22-24 October 2015.

Van de Ven, A., \& Rogers, E. (1988). Innovations and organizations: Critical perspectives. Communication Research, 15, 623-651. https://doi.org/10.1177/009365088015005007

Van de Ven, A. H. (1986).Central problems in the management of innovation. Management Science, 32, 590-607. https://doi.org/10.1287/mnsc.32.5.590

West, M. A., \& Farr, J. L. (1990). Innovation at work. West, M.A. and Farr, J.L. (Eds.), Innovation and Creativity at Work: Psychological and Organizational Strategies. Wiley, Chichester, UK, pp. 3-14.

Zeleny, M. (2005). Knowledge of enterprise: knowledge management or knowledge technology? In: Governing and Managing Knowledge in Asia, Menkhoff, T., Evers, H.-D. \& Chay, Y. W., eds, 23-61, World Scientific Publishing, Vol. 3, ISBN 981256-193-5, Singapure.

\section{Copyright Disclaimer}

Copyright for this article is retained by the author(s), with first publication rights granted to 
the journal.

This is an open-access article distributed under the terms and conditions of the Creative Commons Attribution license (http://creativecommons.org/licenses/by/4.0/). 